\title{
Green Synthesis of Silver Nanoparticles Using Melia Azedarach and its Characterization, Corrosion and Antibacterial Properties
}

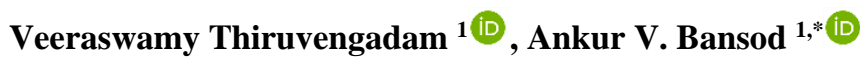 \\ 1 Department of Mechanical Engineering, Vel Tech Rangarajan Dr.Sagunthala R\&D Institute of Science and Technology, \\ Avadi, Chennai, India; thiru_vengadam73@yahoo.co.in (V.T); ankur.1754@gmail.com (A.V.B); \\ * Correspondence: ankur.1754@gmail.com;
}

Scopus Author ID 57190381539

Received: 1.07.2020; Revised: 27.07.2020; Accepted: 1.08.2020; Published: 2.08.2020

\begin{abstract}
Nanoparticle synthesis by the biological method is economical and environmentally friendly. In the present study, the biosynthesis of silver nanoparticles is performed by using extracts of Melia Azedarach plant leaves. The synthesis is performed by adding to the silver nitrate solution to the leaf extract of Melia azedarach. The color change state the precipitation of nanoparticles of silver. The silver nanoparticles obtained were characterized by various techniques such as X-ray diffraction (XRD), Scanning electron microscope (SEM), transmission electron microscope (TEM), and Energy dispersive spectroscopy (EDX). The XRD analysis shows the particle size of $11 \mathrm{~nm}$ calculated by the DebyeScherrer. The microstructure analysis shows silver particles of spherical and triangular. The corrosion rate was found to be $0.025 \mathrm{mpy}$. The green silver nanoparticle (AgNPs) synthesized have better antimicrobial potential against both bacteria's (Bacillus subtilis and Pseudomonas aeruginosa).
\end{abstract}

Keywords: Melia Azedarach; Biosynthesis; Potentiodynamic Polarization; Antimicrobial activity.

(C) 2020 by the authors. This article is an open-access article distributed under the terms and conditions of the Creative Commons Attribution (CC BY) license (https://creativecommons.org/licenses/by/4.0/).

\section{Introduction}

The development and use of nanoparticles in recent years have evolved various methods to synthesize nanoparticles. It provides the ability to change the properties of the materials by changing their sizes and shapes. Metal nanoparticles have unique chemical and physical properties compared to bulk materials due to their high surface area to volume ratio [1]. Silver nanoparticles have good electrical conductivity, chemical stability, and better antimicrobial activity. These properties make the silver nanoparticles to be used in medical and electrical applications. Generally, there are two methods to synthesis nanoparticles, i.e., Topdown method (Physical methods) and Bottom-down method (chemical and biological methods). The physical method employs machining and etching processes to produce nanoscale structures, whereas. The chemical method employs chemicals such as sodium borohydride, ethanol, ethylene glycol, etc. as reducing agents [2,3]. The major advantage of using the green synthesis method is the easy availability of the plant extracts, which are economical, safe, and nontoxic, and they have plenty of metabolites that contribute to the reduction of silver ions [4]. All plants (herb, shrubs, or trees) containing lignin, hemicellulose, pectins, flavonoids, phenols, alcohols, and proteins which can produce the AgNPs from the silver salts [5]. The nature of the plant extract influences the kind and size of nanoparticles. This due to the different biomolecules present in the different plant extracts. The biomolecules 
present in the plant extract reduce the monovalent silver ion, and these atoms aggregate to form silver nanoparticles [6]. The AgNPs of a mean size of $16 \mathrm{~nm}$ were obtained by using red apple fruit extract [7]. The Azadirachta Indica leaf extract was used to green synthesis nanoparticle (AgNPs), which contains flavonoids and terpenoids. The particle size of $34 \mathrm{~nm}$ was found to have good antimicrobial properties against Staphylococcus aureus and Escherichia coli microorganisms [8]. The AgNps synthesized using the aqueous leaf extract of Brassica rapa var.japonica plant revealed that they have a good antibacterial property and are less toxic. The AgNPs obtained by the green synthesis method is more stable than the commercial AgNPs available [9]. The spherical shape nanoparticles were observed with a size of $16 \mathrm{~nm}$ with the leaf extract of Budleja globasa hope [10]. Ponarulselvam et al. observed the Ag nanoparticles of 10-30 nm were obtained by using Chenopodium album leaf extract. Transmission electron microscope (TEM) images revealed the formation of spherical nanoparticles at higher concentrations of the leaf extracts [11]. The silver nanoparticle has been reported to be the most effective against microbial activities [12,13]. Many researchers have reported the use of silver and silver nanoparticles in medical applications like medial health care and dental materials [14]. However, many bacteria have developed resistance against most of the medicine, which results in lower efficiency. Hence, in this study, silver nanoparticle was synthesized using Melia Azedarach plant leaves. The characterization and antibacterial potential of the AgNPs against the Bacillus subtilis and Pseudomonas aeruginosa were evaluated. As there is no report concerning the green synthesis AgNPs with Melia Azedarach plant leaves followed by antimicrobial activity with the above bacteria.

\section{Materials and Methods}

Melia Azedarach plant leaves were carefully washed in water and then rinsed in deionized water to get rid of the dirt present in the leaves. The leaves were dried in sunlight to remove moisture and ground into powder form. Deionized water $(100 \mathrm{ml})$ was taken in a conical flask, and $5 \mathrm{~g}$ of the leaf extract (present in powder form) were mixed. The prepared mixture is stirred by using a magnetic stirrer at $50{ }^{\circ} \mathrm{C}$ for 1 hour. The solution is then cooled at room temperature, and Watt's man, No1 filter paper, was employed to filter the remaining extract. For the preparation of a silver nitrate solution, $100 \mathrm{ml}$ of deionized water was taken and mixed with $1.67 \mathrm{~g}$ of $\mathrm{AgNO}_{3}$ to produce $0.1 \mathrm{M}$ of the aqueous $\mathrm{AgNO}_{3}$ solution. The solution was then stirred in a conical flask with a magnetic stirrer apparatus. The biosynthesis of silver nanoparticles was prepared by adding to a $20 \mathrm{ml}$ aqueous silver nitrate solution with $20 \mathrm{ml}$ of Melia Azedarach leaf extract. The change of solution color was observed from colorless to light yellow. This may be due to the formation of AgNPs [15]. The solution is stirred in a magnetic stirrer apparatus maintained at a $60{ }^{\circ} \mathrm{C}$ temperature for one hour. The dark black color is observed after heating, which emphasizes the development of nanoparticles of silver [15]. The solution obtained after precipitation of AgNPs is dried in a Petri dish, and the silver nanoparticles powder is collected for characterization and antimicrobial activity testing. The preparation of the process is shown in Figure 1 and Figure 2. X-ray diffraction (XRD, D8 Advance, Bruker) was carried out for the sample using $\mathrm{Cu} \mathrm{K} \alpha$ radiation at $30 \mathrm{kV}$. XRD pattern was recorded in the $2 \theta$ range between 10 and 800 at a scan speed of $2 \%$ min. The crystal size was calculated using the Debye-Scherrer formula as given in Eq. 1 [16].

$$
t(n m)=\frac{0.9 \lambda}{\beta \operatorname{Cos} \theta}
$$


Where, Where $\lambda$ is the wavelength of the X-ray used (1.5418 $\AA$ ), $\beta$ is the full width at half maximum (FWHM) in radians and $\theta$ is the angle of the reflection. The crystallinity was also calculated using Eq. 2 [17].

$$
\text { Crystallinity }=\frac{\text { area of crystalline peak }}{\text { area of all peaks }} \times 100
$$

For microstructural analysis, a scanning electron microscope (SEM VEGA3-TESCAN) was used. Transmission electron microscope (TEM FEI-TECNAI G2-20 TWIN) was also carried out with an accelerating voltage of $200 \mathrm{kV}$. The silver nanoparticles film was placed on carbon-coated TEM grids and were analyzed. Antimicrobial test (disc diffusion method) was performed against two bacteria's namely Bacillus subtilis and Pseudomonas aeruginosa. Antibacterial activity was evaluated by using the Himedia zone reader [18].
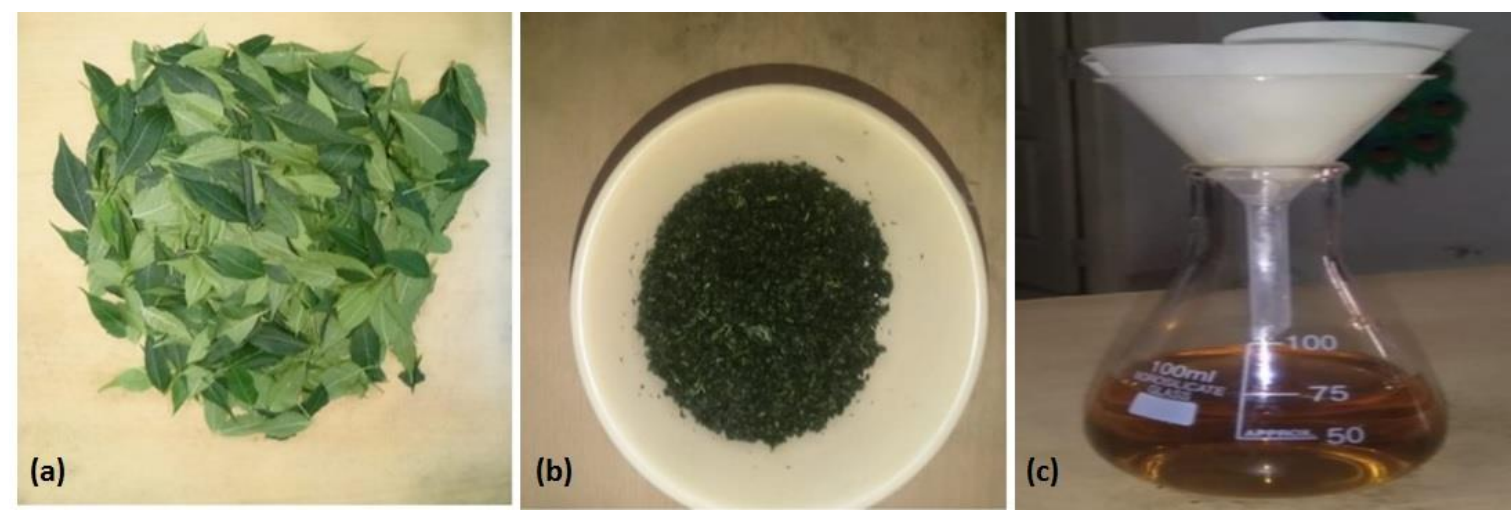

Figure 1. Preparation of leaf extract.
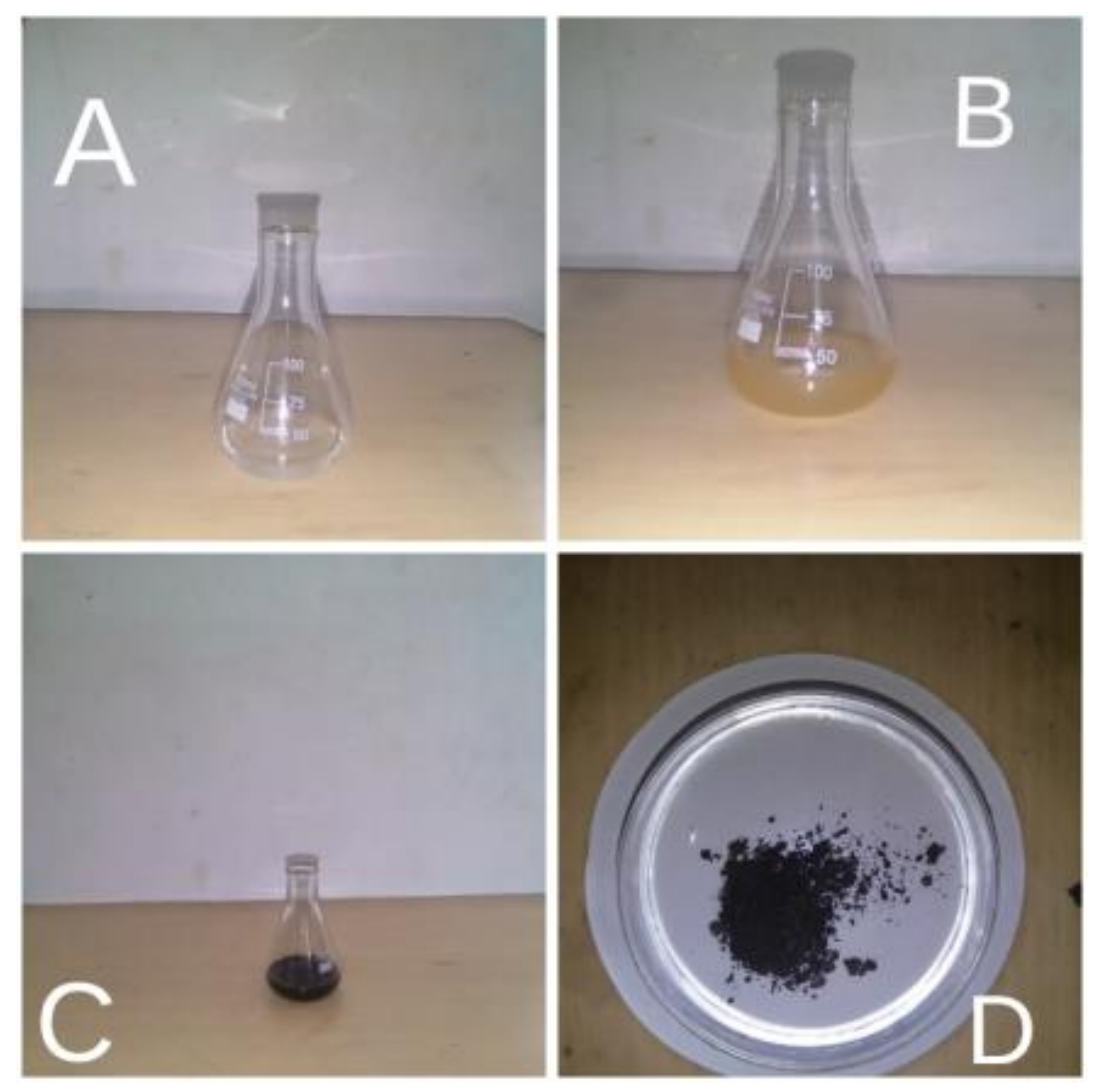

Figure 2. Melia Azedarach assisted green synthesis (a) $\mathrm{AgNO}_{3}$ solution (b) $\mathrm{AgNO}_{3}$ solution after adding plant extract (c) Synthesized Silver nanoparticles (d) AgNPs. 


\section{Results and Discussion}

\subsection{X-Ray diffraction spectroscopy.}

Figure 3 shows the X-ray diffraction (XRD) peak analysis of the silver nanoparticle. The XRD peaks were observed at $2 \theta$ values of 37.08, 43.28, 63.48, and 77.51. The XRD peaks at $2 \theta$ values of $37.09\left(\mathrm{Ag}_{2} \mathrm{O}\right), 43.21(\mathrm{Ag} / \mathrm{AgO}), 63.46\left(\mathrm{Ag}_{2} \mathrm{O}\right)$, and $76.46(\mathrm{Ag})$. This corresponds to (111), (200), (220) and (311) crystallographic planes of the AgNPs. The high intensity of the peak at 37.08 shows the maximum crystallinity of silver nanoparticles. It was reported that the formation of $\mathrm{Ag}$ from $\mathrm{AgO}$ mainly occurs at room temperature [19]. The broader peak at higher theta $(\theta)$ values represents a bigger size crystalline. It was observed that the average grain size was found to be $11 \mathrm{~nm}$. Raza et al. reported that the peak at $\theta$ of 37.08 shows spherical shape nanoparticle having an FCC structure [20]. The crystallinity was calculated from Eq. 2. The area of the crystalline peak and area of all the peak was calculated to be 213.94 and 250.3. Hence crystallinity of the prepared silver nanoparticle was found to be $85.09 \%$.

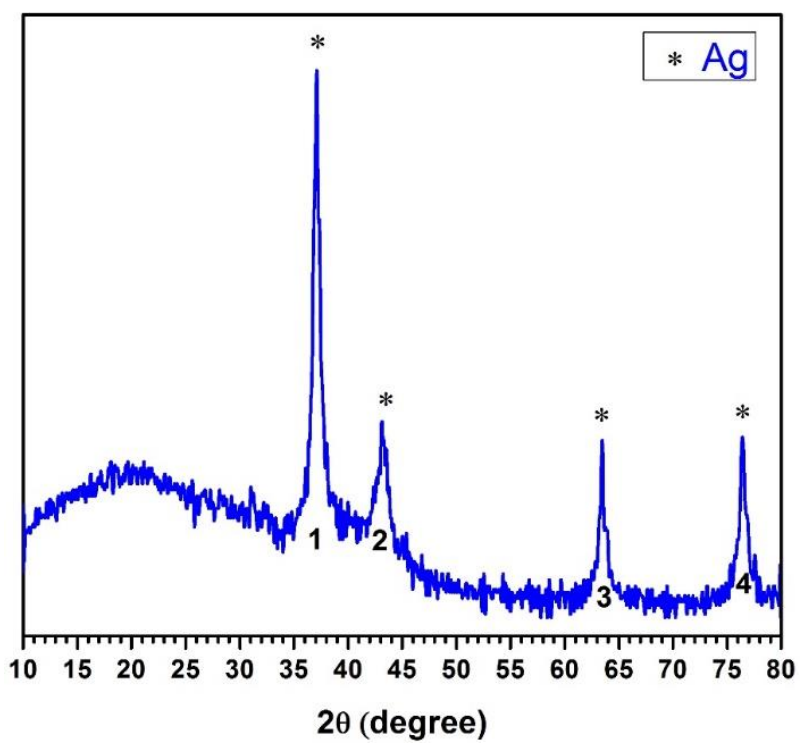

Figure 3. XRD analysis of silver nanoparticles.

Table 1. XRD results of nanoparticles.

\begin{tabular}{c|c|c|c|c} 
Peak No & 2-theta $(\mathbf{a n g})$ & d $(\mathbf{a n g})$ & FWHM $(\mathbf{a n g})$ & D $(\mathbf{n m})$ \\
\hline 1 & 37.09 & 2.4227 & 0.80 & 10.38 \\
\hline 2 & 43.21 & 2.089 & 1.07 & 7.97 \\
\hline 3 & 63.46 & 1.4649 & 0.74 & 12.56 \\
\hline 4 & 76.46 & 1.2306 & 0.77 & 13.07 \\
\hline
\end{tabular}

\subsection{Fourier-transform infrared spectroscopy (FTIR).}

Figure 4 shows the FTIR analysis of silver nanoparticles. FTIR measurements were carried out to measure the presence of various groups in the bioreduction of silver nanoparticles. The observed peaks of FTIR were compared with the standard values of the functional group. The results show the spectra at 3273.07, 2923.07, 1603.00, 1321.99, 1039.30, $821.21 \mathrm{~cm}^{-1}$. The bands at 3273.07 show the presence of $\mathrm{O}-\mathrm{H}$ stretching vibration. This corresponds to alcohol and phenol groups - the peak at 2923.07 forms due to C-H stretching 
of compounds. The peak at 1603.00 shows the presence of C-N and C-C, which represents the presence of proteins. The band at 1321.99 resembles the presence of a nitro compound with $\mathrm{N}=\mathrm{O}$. The peak at 1039.30 exemplifies $\mathrm{N}-\mathrm{H}$ and $\mathrm{C}-\mathrm{H}$, which designate the presence of protein in the compound. The FTIR analysis shows dual characteristics of protein in the Melia Azedarach and does not affect due to the interaction with the $\mathrm{Ag}^{+}$nanoparticle.

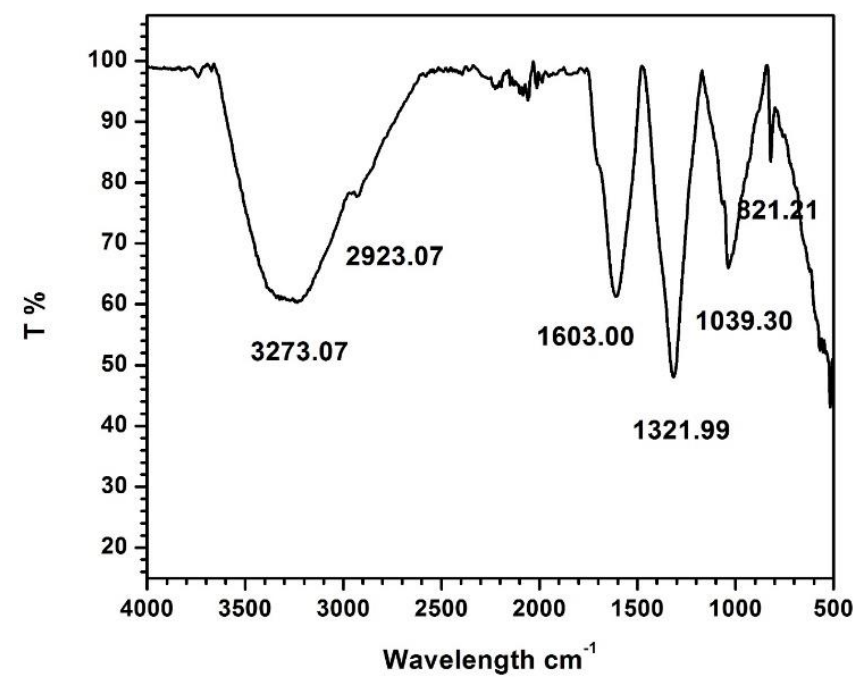

Figure 4. FTIR of silver nanoparticles.

\subsection{Scanning electron micrograph (SEM) analysis.}

Figure 5 shows a micrograph of silver nanoparticles using a scanning electron microscope (SEM). The SEM analysis shows triangular and spherical structures. Some of the researchers had observed rod-like structure in their microstructure [21,22], for analysis of size particle. Image $\mathbf{J}$ software was used. The obtained values were used to determine the mean, standard distribution by using IBM SPSS statistical software. SEM image revealed the AgNPs produced by using the extract of the Melia azedarch leaf are in the range of 6 to $12 \mathrm{~nm}$. The variation in the size of the AgNPs is since the nanoparticles are formed at various durations [23]. The grain size of AgNPs of SEM supports the findings of XRD analysis.

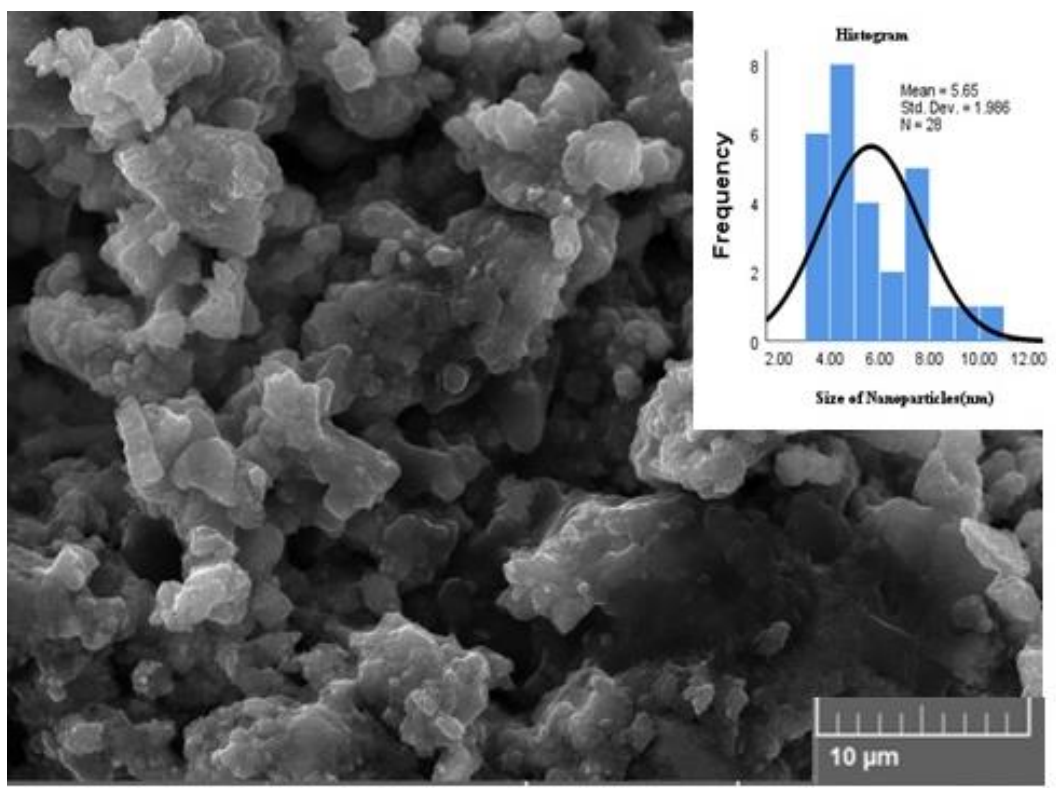

Figure 5. Scanning electron microscope image showing the size distribution of $\mathrm{Ag}$ nanoparticles and the corresponding histogram. 
3.4. Transmission electron microscope (TEM) and Energy dispersive spectroscopy (EDS) analysis

Figure $6(\mathrm{a}$ and $\mathrm{b}$ ) shows the morphology and size of the particles analyzed using a high-resolution transmission electron microscope. The selected area electron diffraction (SAED) pattern shows the ring-like diffraction pattern, which indicates that the particles are crystalline.
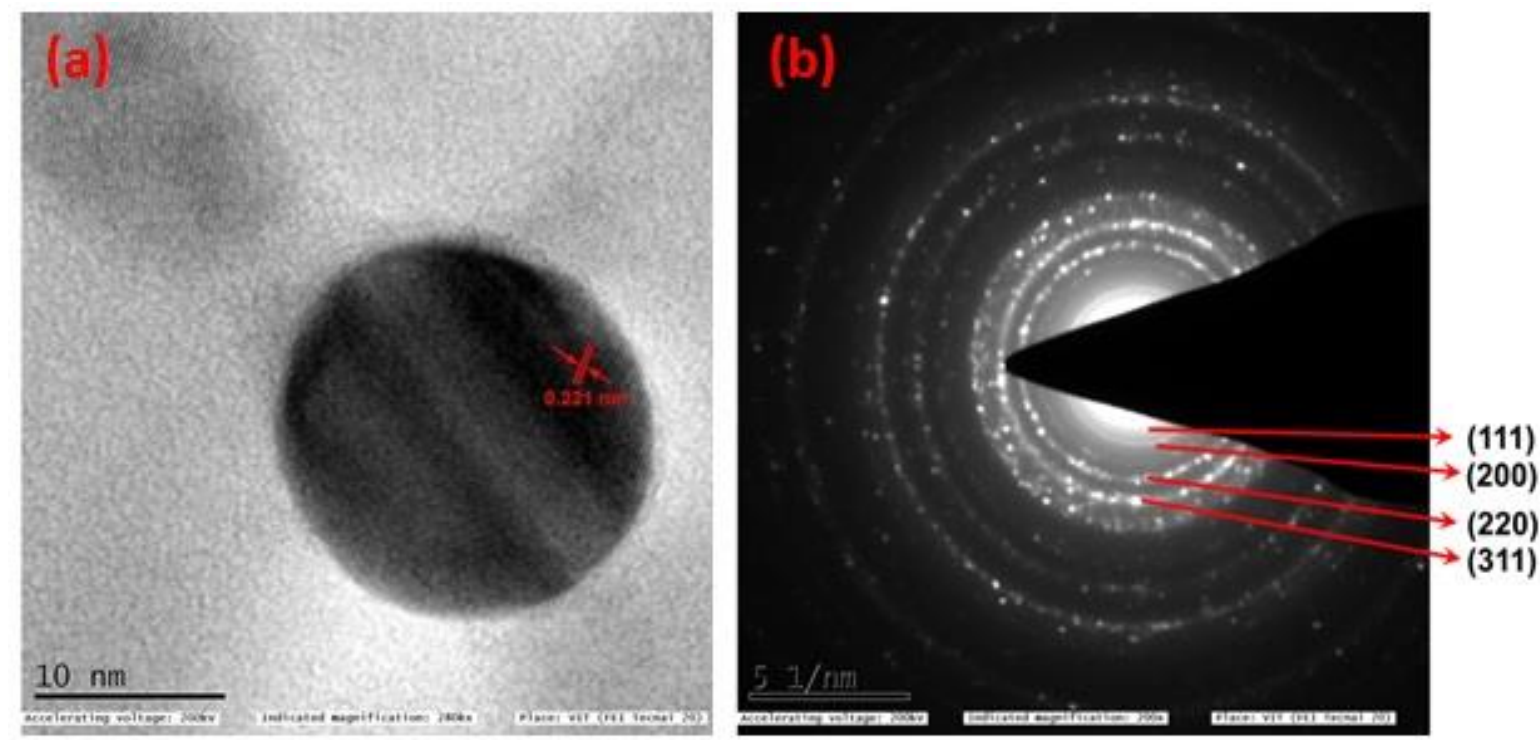

Figure 6. HRTEM micrograph (a) image shows d spacing (b) SAED pattern of Ag nanoparticle.
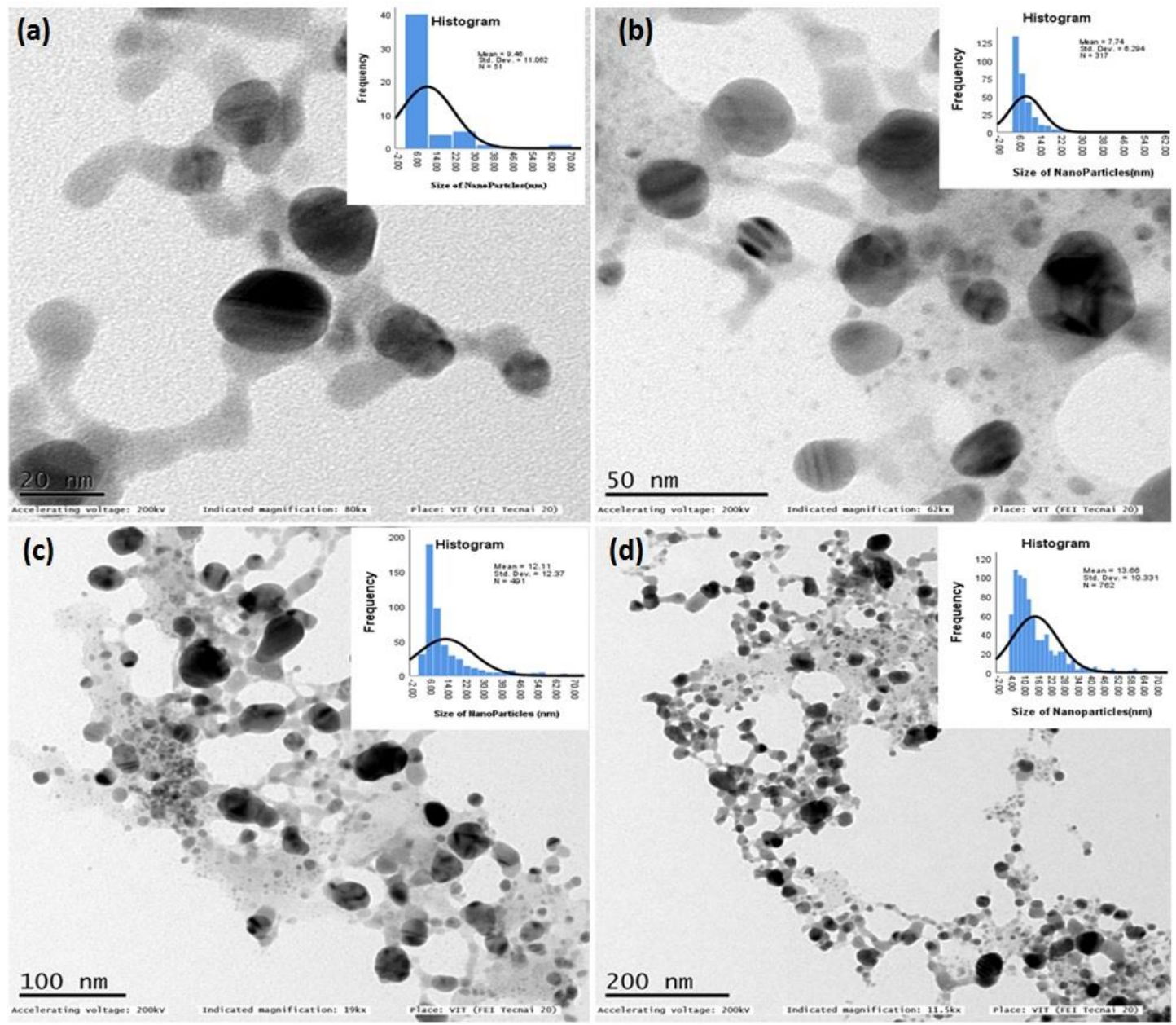

Figure 7. HRTEM Image (a-d) showing the distribution of AgNPs and corresponding histograms. 
The diffraction rings may be indexed based on the FCC structure of silver. The four rings formed due to reflections from (111) (200), (220) and (311) lattice planes of the FCC silver structure, respectively. Song et al. reported similar SAED pattern [24]. Figure 7 (a to d) shows the TEM micrograph of silver nanoparticles at $20 \mathrm{~nm}, 50 \mathrm{~nm}, 100 \mathrm{~nm}, 200 \mathrm{~nm}$. It was observed that the particle size with variable shape. However, most of them show the spherical shape in nature with some triangular morphology. Similar observed by SEM micrograph. The majority of the nanoparticles were observed to be scattered with a few of them showing aggregates of different sizes as observed under TEM micrograph. To obtain the particle size of silver nanoparticles, Image $\mathbf{J}$ software was used. The data obtained were used to draw the frequency distribution histogram using IBM statistics software. The particles are nearly spherical nature with a particle size of $10.20 \pm 2 \mathrm{~nm}$. EDS analysis also confirms the formation of the silver particle, as shown in Figure 8.

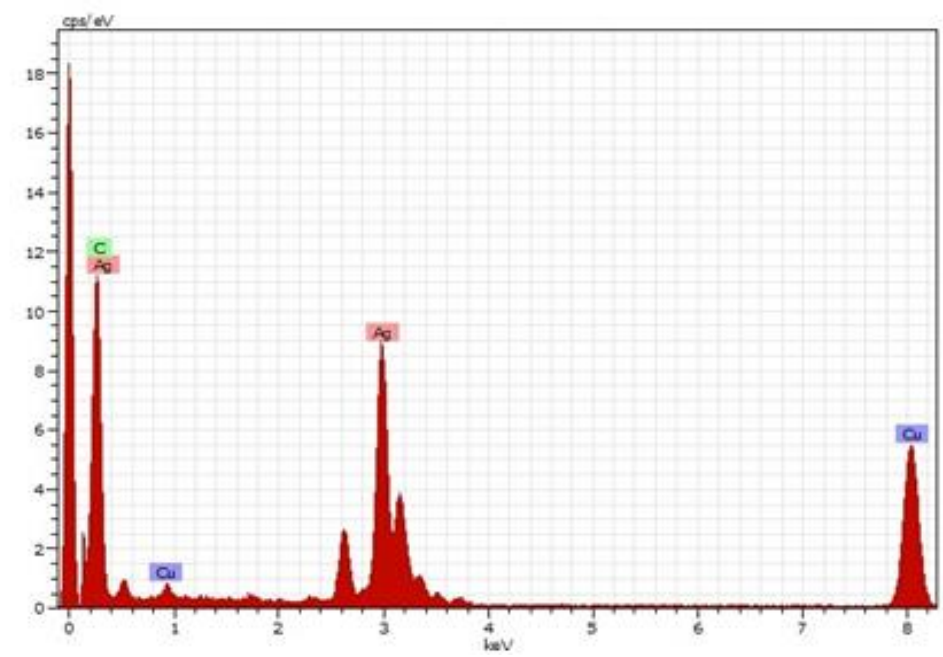

Figure 8. EDS analysis of silver nanoparticles.

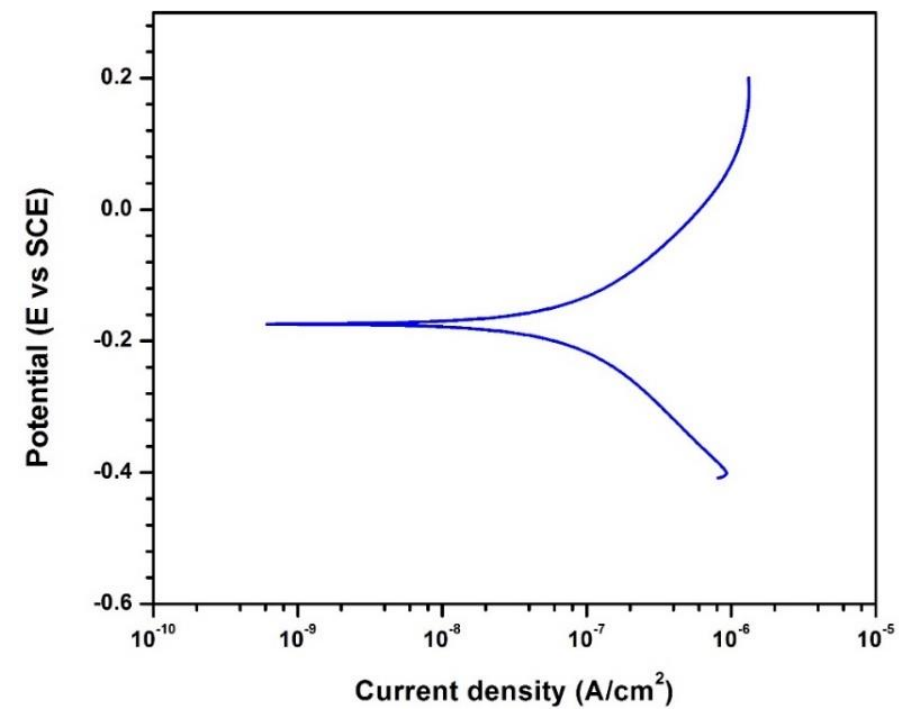

Figure 9. Potentiodynamic polarization of silver nanoparticles.

\subsection{Potentiodynamic polarization.}

Figure 9 shows the potentiodynamic polarization of $\mathrm{Ag}$ nanoparticle. These studies were carried out at room temperature $\left(30 \pm 2^{\circ} \mathrm{C}\right)$ in $3.5 \% \mathrm{NaCl}$ test solutions at a scan rate of $0.1667 \mathrm{mV} / \mathrm{s}$. Three electrode electrochemical cell was used for the corrosion test. Where platinum was used as a counter electrode, the sample is used as a working electrode and a 
reference electrode as a saturated calomel electrode. The corrosion rate was calculated according to Eq 3 [25].

$$
C R(m p y)=\frac{0.129 \times a \times i c o r r}{n \times D}
$$

Where $\mathrm{a}$ is the atomic weight, $i_{\text {corr }}$ is the corrosion current density in $\mu \mathrm{A} / \mathrm{cm}^{2}, \mathrm{n}$ is the valence, and $\mathrm{D}$ is the density in $\mathrm{g} / \mathrm{cm}^{3}$. The value of $i_{\text {corr }}$ was found to be $0.087 \mu \mathrm{A} / \mathrm{cm}^{2}$ using Tafel slope. Hence the corrosion rate of the sample was found to be $0.025 \mathrm{mpy}$.

\subsection{Antibacterial activity.}

AgNPs synthesized using the extract of Melia azedarach leaves were screened for antimicrobial potential against two bacteria, namely Bacillus subtilis and Pseudomonas aeruginosa by agar well diffusion method [26]. The AgNPs were taken in a concentration of $25,50,75,100 \mu \mathrm{g}$, as shown in Figure 10. The standard drug streptomycin $(20 \mu \mathrm{g})$ was used as a positive reference standard to decide the sensitivity of each microbial activity. The results show the green synthesis of silver particle shows inhibition zones. Both the bacteria's have inhibition effects as Pseudomonas aeruginosa shows better antibacterial properties as compared to Bacillus subtilis, as shown in Table 2. This may be due to the less toxicity of AgNPs with Pseudomonas aeruginosa, which is mainly due to oxidative stress and independent of silver ions [27]. It was reported that the decrease in particle size shows a lower resistance against the microbial activity. The spherical shape of nanoparticle observed in TEM analysis has influenced the antimicrobial properties [28].
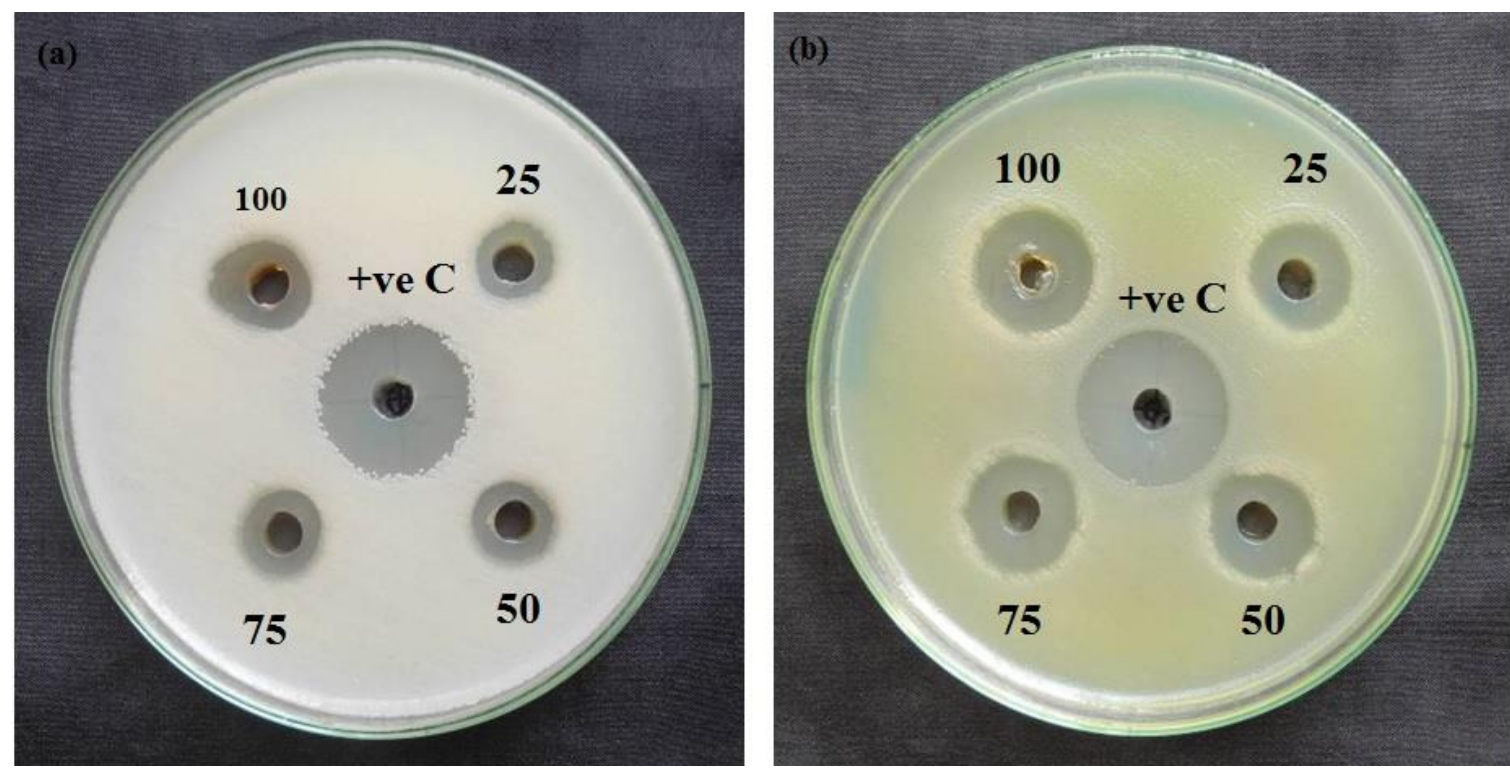

Figure 10. AgNPs showing antibacterial activity against human pathogenic (a): Bacillus subtilis.

(b): Pseudomonas aeruginosa.

Table 2. Zones of inhibition at various concentrations.

\begin{tabular}{c|c|c|c|c|c|c}
\multirow{2}{*}{ S. No } & \multirow{2}{*}{ Microorganism } & \multicolumn{5}{|c}{ Zone of inhibition $(\mathbf{m m})$} \\
\cline { 3 - 7 } & \multirow{2}{*}{$\begin{array}{c}\text { Positive } \\
\text { Control }\end{array}$} & 25 & 50 & 75 & 100 \\
\cline { 3 - 7 } & Bacillus subtilis & 25 & 08 & 09 & 10 & 12 \\
\hline 1 & $\begin{array}{c}\text { Pseudomonas } \\
\text { aeruginosa }\end{array}$ & 25 & 12 & 15 & 18 & 21
\end{tabular}




\section{Conclusions}

In this study, the AgNPs were successfully synthesized by using the green synthesis method. The production of $\mathrm{Ag}$ particles with this method involves involving less cost and environmentally friendly. The produced silver nanoparticle was characterized using various techniques such as XRD, HRTEM, FTIR, and EDX. It was found that silver nanoparticle consists of a crystalline nature as confirmed by X-ray diffraction and TEM. The X-Ray diffraction implied the average crystalline size of $11 \mathrm{~nm}$, calculated by employing the DebyeScherrer formula. HRTEM also implied the formation of an AgNPs particle size range of $10.20 \mathrm{~nm} \pm 2 \mathrm{~nm}$. EDX analysis confirms the Ag peak. AgNPs here exhibited acceptable zones of inhibition against Bacillus subtilis and Pseudomonas aeruginosa bacteria as more antibacterial properties were shown by Pseudomonas aeruginosa. The corrosion rate was found to be 0.025 mpy. Thus the research implies that Melia Azedarach leaves extract has been one of the best methods for the synthesis of AgNPs.

\section{Funding}

This research received no external funding.

\section{Acknowledgments}

The authors are grateful to the School of Advanced Science (SAS), Vellore Institute of Technology, Vellore, India, for providing HRTEM facility for characterization and Avanz BioLab, Chennai, India for performing an antimicrobial test of the AgNPs.

\section{Conflicts of Interest}

The authors declare no conflict of interest.

\section{References}

1. Said, S.; Mikhail, S.; Riad, M. Recent processes for the production of alumina nanoparticles. Mater. Sci. Energy Technol. 2020, 3, 344-363, https://doi.org/10.1016/j.mset.2020.02.001.

2. Kumar, S.; Das, S.K.; Pattanayek, S.K. Evolution of nanostructure and mechanical properties of silver nanoparticle in the confined region between graphene sheets: An atomistic investigation. Comput. Mater. Sci. 2018, 152, 393-407, https://doi.org/10.1016/j.commatsci.2018.06.021.

3. Murugan, N.: Natarajan, D. Bionanomedicine for antimicrobial therapy - a case study from Glycosmis pentaphylla plant mediated silver nanoparticles for control of multidrug resistant bacteria. Lett. Appl. NanoBioScience 2018, 8, 523-540. https://doi.org/10.33263/LIANBS834.523540.

4. Chandra, H.; Kumari, P.; Bontempi, E.; Yadav, S. Medicinal plants: Treasure trove for green synthesis of metallic nanoparticles and their biomedical applications. Biocatal. Agric. Biotechnol. 2020, 24, https://doi.org/10.1016/j.bcab.2020.101518.

5. Katta, V.K.M.; Dubey, R.S. Green synthesis of silver nanoparticles using Tagetes erecta plant and investigation of their structural, optical, chemical and morphological properties. Mater. Today Proc. 2020, https://doi.org/10.1016/j.matpr.2020.02.809.

6. Tippayawat, P.; Phromviyo, N.; Boueroy, P.; Chompoosor, A. Green synthesis of silver nanoparticles in aloe vera plant extract prepared by a hydrothermal method and their synergistic antibacterial activity. Peer $J$ 2016, 1-15, https://doi.org/10.7717/peerj.2589.

7. Kazlagić, A.; Abud, O.A.; Ćibo, M.; Hamidović, S.; Borovac, B.; Omanović-Mikličanin, E. Green synthesis of silver nanoparticles using apple extract and its antimicrobial properties. Health Technol. (Berl). 2019, 10, 147-150, https://doi.org/10.1007/s12553-019-00378-5.

8. Ahmed, S.; Ahmad, M.; Swami, B.L. Green synthesis of silver nanoparticles using Azadirachta indica aqueous leaf extract. J. Radiat. Res. Appl. Sci. 2015, 9, 1-7, https://doi.org/10.1016/j.jrras.2015.06.006.

9. Akter, M.; Rahman, M.M.; Ullah, A.K.M.A.; Sikder, M.T.; Hosokawa, T.; Saito, T.; Kurasaki, M. Brassica rapa var. japonica Leaf Extract Mediated Green Synthesis of Crystalline Silver Nanoparticles and Evaluation of Their Stability, Cytotoxicity and Antibacterial Activity. J. Inorg. Organomet. Polym. Mater. 2018, 28, 
1483-1493, https://doi.org/10.1007/s10904-018-0818-7.

10. Carmona, E.R.; Benito, N.; Plaza, T.; Recio-Sánchez, G. Green synthesis of silver nanoparticles by using leaf extracts from the endemic Buddleja globosa hope. Green Chem. Lett. Rev. 2017, 10, 250-256, https://doi.org/10.1080/17518253.2017.1360400.

11. Ponarulselvam, S.; Panneerselvam, C.; Murugan, K.; Aarthi, N.; Kalimuthu, K.; Thangamani, S. Synthesis of silver nanoparticles using leaves of Catharanthus roseus Linn. G. Don and their antiplasmodial activities. Asian Pac. J. Trop. Biomed. 2012, 2, 574-580, https://doi.org/10.1016/S2221-1691(12)60100-2.

12. Ahmed, S.; Ullah, S.; Ahmad, M.; Swami, B.L.; Ikram, S. Green synthesis of silver nanoparticles using Azadirachta indica aqueous leaf extract. J. Radiat. Res. Appl. Sci. 2015, 9, 1-7, https://doi.org/10.1016/j.jrras.2015.06.006.

13. Singh, A.; Gautam, P.K.; Verma, A.; Singh, V.; Shivapriya, P.M.; Shivalkar, S.; Sahoo, A.K.; Samanta, S.K. Green synthesis of metallic nanoparticles as effective alternatives to treat antibiotics resistant bacterial infections: A review. Biotechnol. Reports 2020, 25, https://doi.org/10.1016/j.btre.2020.e00427.

14. Jyoti, K.; Baunthiyal, M.; Singh, A. Characterization of silver nanoparticles synthesized using Urtica dioica Linn . leaves and their synergistic effects with antibiotics. J. Radiat. Res. Appl. Sci. 2015, 9, 1-11, https://doi.org/10.1016/j.jrras.2015.10.002.

15. Lakshmanan, G.; Sathiyaseelan, A.; Kalaichelvan, P.T.; Murugesan, K. ScienceDirect Plant-mediated synthesis of silver nanoparticles using fruit extract of Cleome viscosa L .: Assessment of their antibacterial and anticancer activity. Karbala Int. J. Mod. Sci. 2017, 4, 1-8, https://doi.org/10.1016/j.kijoms.2017.10.007.

16. Heinz, M.; Srabionyan, V.V.; Bugaev, A.L.; Pryadchenko, V.V.; Ishenko, E.V.; Avakyan, L.A.; Zubavichus, Y.V.; Ihlemann, J.; Meinertz, J.; Pippel, E.; Dubiel, M.; Bugaev, L.A. Formation of silver nanoparticles in silicate glass using excimer laser radiation: Structural characterization by HRTEM, XRD, EXAFS and optical absorption spectra. 2016, 681, 307-315, https://doi.org/10.1016/j.jallcom.2016.04.214.

17. Fewster, P.F. X-ray analysis of thin films and multilayers. Reports Prog. Phys. 1999, 59, 1339-1407, https://doi.org/10.1088/0034-4885/59/11/001.

18. Kalyani, L.; Naga, P.; Kumar, V.; Pammi, S.V.N.; Swamy, V.; Ramana, V.; Kolapalli, M. in Semiconductor Processing Synergetic antibacterial and anticarcinogenic e ff ects of Annona squamosa leaf extract mediated silver nano particles. Mater. Sci. Semicond. Process. 2019, 100, 301-309, https://doi.org/10.1016/j.mssp.2019.05.007.

19. Dorobantu, S.; Burrell, E.; Goss, G. Effect of light on physicochemical and biological properties of nanocrystalline silver dressings. RSC Adv 2015, 5, 14294-14304, https://doi.org/10.1039/C4RA15745A.

20. Raza, M.A.; Kanwal, Z.; Rauf, A.; Sabri, A.N.; Riaz, S.; Naseem, S. Size- and Shape-Dependent Antibacterial Studies of Silver Nanoparticles Synthesized by Wet Chemical Routes. Nanomaterials 2016, 6, https://doi.org/10.3390/nano6040074.

21. Anuj, S.A.; Gajera, H.P.; Hirpara, D.G.; Golakiya, B.A. Bacterial membrane destabilization with cationic particles of nano-silver to combat e ffl ux-mediated antibiotic resistance in Gram-negative bacteria. Life Sci. 2019, 230, 178-187, https://doi.org/10.1016/j.lfs.2019.05.072.

22. Sadeghi, B.; Garmaroudi, F.S.; Hashemi, M.; Nezhad, H.R.; Nasrollahi, A.; Ardalan, S.; Ardalan, S. Comparison of the antibacterial activity on the nanosilver shapes: Nanoparticles, nanorods and nanoplates. Adv. Powder Technol. 2012, 23, 22-26, https://doi.org/10.1016/j.apt.2010.11.011.

23. Ibrahim, H.M.M. Green synthesis and characterization of silver nanoparticles using banana peel extract and their antimicrobial activity against representative microorganisms. J. Radiat. Res. Appl. Sci. 2015, 8, 1-11, https://doi.org/10.1016/j.jrras.2015.01.007.

24. Yong, J.; Beom, S.Æ.; Kim, S. Rapid biological synthesis of silver nanoparticles using plant leaf extracts. 2009, 32, 79-84, https://doi.org/10.1007/s00449-008-0224-6.

25. Bansod, A. V.; Patil, A.P.; Shukla, S. Effect of heat on microstructural, mechanical and electrochemical evaluation of tungsten inert gas welding of low-nickel ASS. Anti-Corrosion Methods Mater. 2018, 65, 605615, https://doi.org/10.1108/ACMM-05-2018-1941.

26. Kumar, V.; Wadhwa, R.; Kumar, N.; Kumar, P. A comparative study of chemically synthesized and Camellia sinensis leaf extract-mediated silver nanoparticles. 3 Biotech 2019, 9, 1-14, https://doi.org/10.1007/s13205018-1544-0.

27. Kim, S.; Eun, J.; Choi, J.; Chung, K.; Park, K.; Yi, J.; Ryu, D. Oxidative stress-dependent toxicity of silver nanoparticles in human hepatoma cells. Toxicol. Vitr. 2009, 23, 1076-1084, https://doi.org/10.1016/j.tiv.2009.06.001.

28. Vu, X.H.; Thanh, T.; Duong, T.; Thu, T.; Pham, H.; Trinh, D.K. Synthesis and study of silver nanoparticles for antibacterial activity against Escherichia coli and Staphylococcus aureus, Adv Nat Sci-Nanosci. 2018, 9 , 025019-025026, https://doi.org/10.1088/2043-6254/aac58f. 